\title{
Implementation of Standard Industrial Classification 2007: December 2009 update
}

\section{SUMMARY}

ONS initially publicised its plans for the implementation of SIC 2007 in Hughes (2008), and this was followed up with an article covering a wider Government Statistical Service angle (Brook and Hughes 2009). This article describes the methodological aspects of the move to SIC 2007; lays out the implications for National Accounts; and gives an update on the timetable for implementation across the Labour Market Statistics outputs, some of the details of which have changed since the previous publication.

\section{Introduction}

$\int$ tandard Industrial Classification (SIC) is a method of classifying businesses by their type of economic activity. The classification is used in the collection and presentation of data across the Government Statistical Service (GSS) and for administrative purposes, and by government and non-government bodies as a convenient way of classifying industrial activities into a uniform and common structure. The UK's SIC has been revised six times since its introduction in 1948, but SIC 2007 represents the first major revision since 1992 and follows a series of consultations in conjunction with a revision of the European Union's industrial classification system.

The implementation of SIC 2007 is reaching a key phase. During the next twelve months, most of the Labour Market Statistics will be published for the first time on a SIC 2007 basis, the short term business surveys will adopt the new classification from the start of 2010 and plans are being put in place for the National Accounts to move onto SIC 2007 in September 2011.

\section{Methodological aspects of changing to SIC 2007}

SIC codes form an integral part of the design of surveys. As such, the change in SIC has initiated a review of the processes involved in each survey - from data collection, through to dissemination of results. This section of the article provides some insights into the changes that are necessary to accommodate SIC 2007, and also describes some of the initiatives that are being introduced to coincide with the introduction of the new classification.

Business register

ONS maintains the Inter-departmental Business Register (IDBR), and uses it as the principal sampling frame for most business surveys. From the start of 2008, the IDBR has been dual-coded, meaning that each of the 2.1 million businesses listed is classified to both a SIC 2003 and a SIC 2007 industry code. The phased timetable for implementation of the new SIC means that some surveys will move to selection by the new SIC earlier than others. The first sample selections made using SIC 2007 as a stratifying variable were the Annual Business Inquiry and PRODCOM (Products of the European Community) in late 2008, and the last selections using SIC 2003 will be for the Stocks and Capital Expenditure surveys in late 2010 or early 2011.

The SIC 2003 codes will be retained on the IDBR until at least the end of 2011 by which time all surveys will be based on the new classification. After this a decision will be made regarding the ongoing maintenance of SIC 2003 on the register. This will be based on their usefulness given the inevitable deterioration in quality of the old codes over time, following adoption of SIC 2007 as the primary classification in early 2008 .

Redesign of surveys - inputs Most of ONS's business surveys are stratified by industry, as well as by size; 
stratification gives greater control over coverage and makes more efficient use of the sample. As part of a rolling programme, each survey is being redesigned so that the survey's industrial strata, which have been formed as groups of SIC 2003 codes, will be replaced by groups of SIC 2007 codes. The new industrial strata have been chosen after consultation with users of the survey outputs. In addition, the boundaries used to form size bands are also under review, and all such changes necessitate a re-allocation of the sample. Together these initiatives should ensure most efficient use is made of the sample in meeting user requirements.

Some of the most visible changes in survey design will be seen by survey respondents, as a number changes relating to data collection are planned.

- Business survey sample selections operate on a rotational basis for smaller businesses; once selected initially for a survey, respondents remain in the sample for a number of periods before being rotated out. Changing the SIC will upset the regular patterns, and, around the time of the change, respondents may remain in the sample for a shorter or longer period than would usually be expected. ONS is trying to limit any additional burden on businesses as much as possible at this time.

- The dual SIC 2003 and SIC 2007 codes mean that some businesses will be classified to different sectors of the economy according to the different SICs. An example is the Publishing industry, which is part of Manufacturing under SIC 2003, and part of Services under SIC 2007. When the SIC 2007 redesigned surveys are implemented, respondents may find they start to receive an alternative questionnaire. The difference may just be in appearance, or it may contain different questions.

- Additional changes to the questionnaires used are also planned, and these will be implemented to coincide with the introduction of SIC 2007 to surveys. These include changes to the names of surveys (a number of current surveys will become part an integrated Monthly/Quarterly Business Survey from January/Q1 2010), and more extensive use is being made of Telephone Data Entry - an alternative to responding via paper questionnaires.

As noted elsewhere, SIC 2007 is being introduced to business surveys in a phased manner, and changes such as those listed have already occurred on a number of surveys, with the remainder being introduced in the near future.

\section{Redesign of survey estimates - outputs}

The presentation of estimates from business surveys with an industrial breakdown is currently based on SIC 2003. Along with the change in survey design, the reporting of outputs will also change to a SIC 2007 basis in the near future, and this will prompt a change to estimates in both first releases and historical back series.

ONS will make some outputs available on both SIC bases for a number of periods, but will be moving towards a SIC 2007 only approach in the future. The first outputs to appear on SIC 2007 are the Annual Business Inquiry and PRODCOM (for reference year 2008), and from the short-term surveys early in 2010. However, as agreed for all European countries the estimates for National Accounts series will continue on SIC 2003 until mid-2011, when the Blue Book will be published using SIC 2007, marking the end of the transition.

ONS will use a mix of two broad approaches in producing estimates on both SIC bases:

- The simplest approach, and one that will be adopted for historic periods, is use of conversion matrices. This method, a macro method, apportions industry estimates based on SIC 2003, and re-aggregates them to form SIC 2007 estimates; the proportions used for the distribution come from data on the IDBR. This method was used by ONS at the time of the last major change in SIC, and has been widely used by other National Statistics Institutes. It is the most practical method to use for historic periods, since dual-coded micro data are not available then.

- For more recent and current-period estimates, ONS will use a micromethod. In this, it is the individual survey responses that are re-weighted and re-aggregated to form the estimates for SIC 2007 based domains (domain estimation), as opposed to apportioning aggregate SIC 2003 estimates. The results using this method are of higher quality than those that would be obtained using conversion matrices, and the SIC 2007 domain estimates can be calibrated to appropriate population totals. ONS plans to use an analogous process to create
SIC 2003 estimates for use in National Accounts from early 2010, when the surveys are redesigned, until mid-2011.

\section{The impact of SIC 2007 on National Accounts}

\section{Timetable}

The phased implementation of SIC 2007 across the ONS has, in the interim before publication of Blue Book in 2011, implications for the UK National Accounts. This is because many of the surveys that feed into the National Accounts will move from being collected on a SIC 2003 basis to being collected on a SIC 2007 basis before SIC 2007 is implemented into the National Accounts. To maintain consistency it will therefore be necessary for the survey outputs that feed into National Accounts to be converted back to a SIC 2003 basis.

\section{The Annual Business Inquiry}

The Annual Business Inquiry (ABI), which is one of the main surveys used in the annual balancing process to produce a consistent single measure of Gross Domestic Product (GDP) in current prices, is based on SIC 2007 from reference year 2008. Data from this survey for 2008 will be required for use in the annual Supply-Use balancing process for the National Accounts in 2010 - one year before the National Accounts are published on a SIC 2007 basis. To produce Blue Book 2010, the ABI data collected on a SIC 2007 basis for 2008 will be used and this will be converted back to a SIC 2003 basis using domain estimation (see the section on Redesign of survey estimates - outputs) for consistency until the full implementation of SIC 2007 in Blue Book 2011. Because of the time required to collect and process the ABI data, the annual balancing is done a year in arrears of the latest full year. Data for 2009 would not be used until 2011.

\section{Quarterly National Accounts}

Most ONS surveys that are used in the quarterly National Accounts will be collected from the first quarter of 2010 on a SIC 2007 basis. These data also will need to be converted back to a SIC 2003 basis until the National Accounts are published on a SIC 2007 basis in September 2011. There are several ways that this will be done within the ONS.

For certain surveys the conversion will be done at a very low level. Domain estimation will be applied to the source data, converting it back to a SIC 2003 basis. This treatment in particular will 
be applied from January 2010 to the Monthly Business Survey, which is being introduced at the same time as the implementation of SIC 2007 and will replace the Monthly Production Inquiry (MPI) and the Monthly Inquiry into the Distributive and Services Sector (MIDSS). These surveys are used to produce the Index of Production (IoP) and the Index of Services (IoS) respectively. The IoP measures the volume of production of the manufacturing, mining and quarrying, and energy supply industries. The IoP is a short-term indicator in its own right and an important indicator of industrial activity. Further information can be found in Walton (2007). The IoS measures the monthly movements in gross valued added (GVA) for the service industries. Further information can be found in Morgan (2006). These are the primary indices used in the calculation for the output measure of GDP. GDP measures the sum of the value added created through the production of goods and services within the economy.

\section{Non-ONS surveys}

Government Statistical Service (GSS) staff in policy departments and the devolved administrations are responsible for the implementation of SIC 2007 for non-ONS surveys or administrative sources that are used in the National Accounts. This activity is being monitored through a GSS Steering Group responsible for co-ordinating the implementation of SIC 2007 across the Government.

With the exception of those for Northern Ireland, very few external sources impact on the National Accounts. The majority of the Northern Ireland sources are regular surveys which mirror key ONS surveys where coverage is limited to Great Britain (GB). GB and Northern Ireland outputs are combined by ONS to produce UK outputs. The Northern Ireland Administration has collaborated with ONS on an implementation timetable to ensure that UK estimates are preserved on a consistent basis for business and household surveys covering key economic outputs.

The other main external source of data that feeds into the National Accounts is from HM Revenue and Customs (HMRC). HMRC provide, on an annual basis, benchmark data that feed into the annual balancing process to determine the estimates of gross trading profits of private non-financial corporations and income data that is used for making estimates of wages and salaries.

\section{Supply and Use Tables}

Most National Accounts statistics are concerned with the composition and value of goods and services entering final demand (for example, purchase by consumers), with the outputs and incomes generated by the economic process. But they do not display the inter-industry transactions which link these activities. The Supply and Use Tables provide this linkage and give a firm basis for compiling a consistent single estimate of GDP at current prices by confronting various sources of data for production (output), expenditure and income in a Supply-and-Use framework. The single estimate of GDP at current prices for a reference year is important for the price adjusted volume estimates of GDP which are derived by applying expenditure deflators or direct volume measures to the reference year current price estimates.

It is important therefore that the levels of detail which are confronted in the Supplyand-Use framework are appropriate and that quality data exists to populate the framework. Currently the levels of detail used in the balancing process are 123 products by 108 industries and this will remain in place for Blue Book 2010. This is slightly smaller than the 123 product by 123 industries framework that had been used by ONS for many years up to Blue Book 2006.

The introduction of SIC 2007 and Classification of Product by Activity (CPA) 2008 with associated changes to their respective industry and product classification dictate that the current dimensions of the Supply and Use Tables will need to change for Blue Book 2011. CPA 2008 is an EU agreed statistical classification of products and services which all member states are legally obliged to use. Within Europe there was a shared view that the product classification should be based on economic origin and therefore replicate the framework of $\mathrm{NACE}^{1}$ Revision 2 at a four digit level, which in turn reflects SIC 2007, the UK interpretation of NACE at a four digit level.

To establish what the new dimensions of the Supply and Use Tables should be ONS went through a process, initially identifying that the minimum requirement that Eurostat required was for data at a two digit level. Recognising that this would not necessarily satisfy users needs ONS then carried out an external consultation in the spring of 2009. Responses were received from more than thirty different organisations and individuals. These included major departments with policy interest, as well as regional interests and those of academics and 'lobby' groups. Most respondents recognised the practical limits on data quality, although many had clear policy needs which were not satisfied by the original proposal. Most made specific requests for additional detail.

All specific requests were evaluated against the following decision criteria:

- Is there a legal requirement? If so, then we should accomodate within the dimensions of the supply-and-use framework.

- Is there a clear user need? If so, does relevant data exist? If so, is the quality of data that exists suitable for producing robust estimates of GDP? If not, is there data available which provide a sound basis for pro-rating estimates down to the required level?

The last point ensured that any desired expansion of the matrix could be populated with actual data. Where these criteria were met, the dimensions of the matrix have been expanded to meet user needs. The main additions to the minimum two digit requirement were mainly related to expanding the transportation and food production categories to aid analysis of their environmental impact. On this basis the review of the consultation concluded that the matrix could be expanded to 114 products by 114 industries. This should result in minimal impact for users.

\section{Modernisation of National Accounts}

The modernisation of the National

Accounts is being addressed under a new programme, ENABLE (Effective National Accounts and Blue Book to measure the Economy). As well as supporting the implementation of SIC 2007 and CPA 2008, the programme will facilitate production of better quality National Accounts, based on transparent procedures which are efficient, reduce the risk of error and free up resources to add value in the production of the accounts. The programme will produce a fully integrated system for the production of balanced estimates of GDP, the National Accounts and the Balance of Payments. The programme has specific focussed objectives which can be completed for use in Blue Book 2011.

For the annual balancing process for the National Accounts leading to the publication of Blue Book 2011 all relevant survey data used will be on a SIC 2007 basis, with back data converted from SIC 2003 to SIC 2007. 
One of the main implications of implementing a significantly revised classification is the treatment of back data. The modernised systems that are being developed by the ENABLE project will have data back to 1997 on a consistent SIC 2007 basis. This will be achieved by converting data at an industry and product level from a SIC 2003 basis to a SIC 2007 basis. This should not result in any overall revisions to the whole economy level because it is just the reclassification of components. The treatment of data before 1997 is yet to be confirmed. ONS has established a project explicitly for the conversion of the long run time series published by National Accounts which go back to 1948 . The project is responsible for the development of suitable methodology to link historic series. It is important to note that, for some very detailed series, it may not be viable to produce robust estimates. Additionally, some industries in the new SIC did simply not exist historically, notably in ICT and financial services.

\section{Implementation of SIC 2007 across Labour Market Statistics outputs}

\section{Background}

In autumn 2008 users were consulted on, and agreed to a plan which meant that most labour market statistics outputs would move to publication of industrial aggregates on the new SIC from June 2010. However, it has recently become clear that there are two necessary deviations from this plan:

\section{Changes to the timetable}

\section{Vacancies Survey}

This will now publish on SIC 2007 from February 2010. In line with other short term business surveys, the Vacancies Survey is due to start sample selection from the IDBR stratified by the new SIC from January 2010. The original plan was to continue converting industrial aggregates back to SIC 2003 until publication in June 2010. However given issues around resources to maintain both series and systems, also in the context of the resources required to support the fundamental redevelopment of the Workforce Jobs systems, this will no longer be possible. The Vacancies Survey industrial aggregates will therefore be published on a SIC 2007 basis once the survey switches to sample selection on the new SIC, that is the January 2010 estimates published in the February 2010
LMS Statistical Bulletin will be on a SIC 2007 basis.

\section{Average Weekly Earnings (AWE)}

The replacement for the Average Earnings Index (AEI) and its associated outputs will now publish on SIC 2007 from October 2010. The short term earnings estimates were also to be published on a SIC 2007 basis from June 2010. However the timing of the National Statistics accreditation of the AWE to replace the AEI, and the associated user demand from the Bank of England and Her Majesty's Treasury for a twelve month publication parallel run for AEI and AWE now mean that the original plan is not sustainable.

The parallel publication of the AEI and AWE began in October 2009 and will run until September 2010. It is not possible to sustain parallel running of both indicators on both the old and new classification bases, therefore the new SIC will not be implemented until the parallel run is complete. The AWE will therefore adopt SIC 2007 in the Labour Market Statistics Statistical Bulletin from October 2010. As it is being discontinued, the AEI will not be migrated to SIC 2007.

Labour Force Survey (LFS) aggregates Users are reminded that, in terms of the switchover of LFS industrial aggregates to a SIC 2007 basis in the Labour Market Statistics Statistical Bulletin, only Table 24 (Redundancies by Industry) is affected. All other LFS tables with an industry breakdown are published in the Historical Quarterly Supplement and these will all convert to a SIC 2007 basis in August 2010, when the April - June 2010 results are published. Table 24 will be published on a SIC 1992 basis up to and including

\section{Table 1}

\section{Summary of revised timings of SIC 2007 publication}

\begin{tabular}{ll}
\hline Source & Planned first publication on SIC 2007 \\
\hline Labour Force Survey & June 2010 (for the Jan-Mar 10 dataset) \\
Annual Population Survey & June 2010 (for the Jan-Dec 09 dataset) \\
Workforce Jobs & June 2010 (for Q1 2010 data) \\
Vacancies & February 2010 (for January 2010 data) \\
Labour Disputes annual article & June 2010 in ELMR \\
Productivity & September 2011 - in line with National Accounts \\
Public Sector Employment & June 2010 (for Q1 2010 data) \\
AWE (AEI replacement) & October 2010 (for August 2010 data) \\
Labour Cost Index & October 2010 (for August 2010 data) \\
Gross Wages and Salaries & October 2010 (for August 2010 data) \\
Annual Business Inquiry ABI/1 & December 09 (for 2008 reference year) \\
Annual Survey of Hours and Earnings ASHE & November 092 (for 2009 reference year - 1st primary output \\
& on SIC 07). \\
\hline
\end{tabular}

Notes:

Source: Office for National Statistics

1 See paragraph on LFS aggregates.

2 Both SIC 2003 and SIC 2007 published in Q1 2009 for 2008 ASHE. 


\section{Summary and next steps}

As mentioned in the section on the redesign of survey estimates, ONS has been using conversion matrices to create historical time series on a SIC 2007 basis. Following the stabilisation of the IDBR on the new basis, ONS is now in a position to make some of these conversion matrices available for wider use. In this regard it is planned to publish three different correlations (based on turnover, employment and count of businesses) on the classification pages of the ONS website in early 2010. In addition, ONS can offer advice on the use of the correlation tables.

Data users will begin to see changes to short term survey outputs from the start of 2010. Monthly and quarterly data will be available on a SIC 2007 basis, starting with the release of the Retail Sales Inquiry (RSI) data on 19 February 2010. For most outputs, complete series on the basis of the new classification will be created using link factors to join sections of the series. However, revisions should be expected as part of later releases as it might take a couple of months for these link factors to settle. The length of back series and their availability will be determined mainly by legislation, but also by what is practical and useful. For example, a series measuring activity in the mobile phone industry prior to the 1980s might not be particularly illuminating. Back series requirements are likely to differ depending on the nature of the data, so ONS will endeavour to publicise its plans in this regard as they become available.

For structural business statistics, there will be no long run back series. ONS is producing $\mathrm{ABI}$ data on both classification bases for both reference years 2007 and 2008 , initially for comparison purposes. $\mathrm{ABI} / 1$ data on both bases with respect to 2008 will be available through NOMIS $^{2}$ on 16 December 2009, whilst a decision on the availability of $\mathrm{ABI} / 2$ data will be made following further analysis.

ONS plans further ELMR articles throughout 2010, some of which will relate to specific data releases on the new basis. These will include details of the impact of the change in classification on the data, the availability of back series and resulting changes to revisions policy.

\section{Notes}

1. NACE is the European Union (EU) classification system for economic activities. The acronym NACE means 'Nomenclature générale des activitiés économiques dans le communautés européennes' although it is known in all member states simply as NACE.
2. NOMIS is a service provided by ONS giving free access to the most detailed and up to date UK labour market statistics from official sources (see www. nomiswebuk.co.uk).

\section{CONTACT}

지elmr@ons.gov.uk

\section{REFERENCES}

Brook K and Hughes J (2009)

'Implementation of SIC 2007 across the Government Statistical Service', Economic \& Labour Market Review, Vol 3 No 8. Available at www.statistics.gov.uk/cci/article. asp?id=2266 Hughes J (2008) 'SIC 2007: Implementation in ONS', Economic \& Labour Market Review, Vol 2 No 8. Available at www.statistics.gov.uk/cci/article. asp? id=2034 Morgan D (2006) 'Summary quality report for Index of Services' Available at www.statistics.gov.uk/cci/article. asp? ID = 1460

Walton A (2007) 'Summary quality report for Index of Production'. Available at www.statistics.gov.uk/CCl/article. asp? ID $=1846$ 